\title{
Feasibility of an oxygen-getter with nickel electrodes in alkaline electrolysers
}

\author{
Daniel Symes $\cdot$ Connie Taylor-Cox $\cdot$ \\ Leighton Holyfield · Bushra Al-Duri • \\ Aman Dhir
}

Received: 4 November 2013/ Accepted: 4 March 2014/Published online: 21 March 2014

(C) The Author(s) 2014. This article is published with open access at Springerlink.com

\begin{abstract}
Alkaline electrolysis is the long-established technology for water splitting to produce hydrogen and has been industrially used since the nineteenth century. The most common materials used for the electrodes are nickel and derivatives of nickel (e.g. Raney nickel). Nickel represents a cost-effective electrode material due to its low cost (compared to platinum group metals), good electrical conductivity and exhibits good resistance to corrosive solutions. The steady degradation of the nickel electrodes over time is known as a result of oxide layer formation on the electrode surface. Reducing oxide layer growth on the electrode surface will increase the efficiency and lifetime of the electrolyser. Titanium has a higher affinity to oxygen than nickel so has been introduced to the electrolyser as a sacrificial metal to reduce oxide layer formation on the nickel. Two identical electrolysers were tested with one difference: Cell B had titanium chips present in the electrolyte solution, whilst Cell A did not have titanium present. SEM results show a reduction of $16 \%$ in the thickness of the Cell B oxide layer on nickel compared to the Cell A nickel, which is supported by the large increase in oxide layer build-up on the titanium in Cell B. EDX on the same samples showed on average a $59 \%$ decrease in oxygen on the Cell B nickel compared to Cell A. XPS surface analysis of the same samples showed a $17 \%$ decrease in the oxygen on Cell B nickel. These results support the hypothesis that adding titanium to an alkaline electrolyser system with
\end{abstract}

\footnotetext{
D. Symes $(\bowtie) \cdot$ C. Taylor-Cox · L. Holyfield · B. Al-Duri ·

A. Dhir

Centre for Hydrogen and Fuel Cell Research, School of Chemical Engineering, University of Birmingham, Edgbaston, Birmingham, West Midlands B15 2TT, UK e-mail: dxs654@bham.ac.uk
}

nickel electrodes can reduce the oxide layer formation on the nickel.

Keywords Oxygen-getter - Hydrogen production - Water electrolysis - Alkaline electrolysis · Electrode degradation . Titanium · Electrolyser

\section{Introduction}

Hydrogen is most commonly produced from fossil fuel sources (approx. 95\%), which is neither sustainable (depletion of fossil fuel resources) and environmentally friendly (produces greenhouse gases as side products) [14]. Water electrolysis represents only $4 \%$ of current hydrogen production, but is a growing area of research and the beginning of commercialisation of water electrolysers has started. The high cost can be attributed to electrical energy prices and the use of platinum group metals (PGMs) as catalysts to improve the efficiency for hydrogen generation [1, 3-6].

A high electrical potential is required to split pure water directly, so an electrolyte is added to reduce the resistance in the system. The most commonly used is a liquid electrolyte $(\mathrm{NaOH}, \mathrm{KOH})$, and there is increasing research on using solid electrolyte in the form of a polymer membrane. This only requires pure water, as well as an electrical energy input [1, 3, 7-11].

The use of caustic solution (typically 25-30 weight \%) in alkaline electrolysers requires the electrodes to exhibit good electrochemical conductivity, high mechanical strength and a strong resistance to corrosion from the caustic environment. Nickel, or a derivative of nickel, is the most commonly used electrode material in commercial alkaline electrolysers, due to its high electrical conductivity 
and its robustness to prolonged exposure in caustic alkaline solution. Although nickel exhibits good electrode lifetime, this duration can be improved and a method for increasing the lifetime of a nickel electrode is investigated herein [3, 6, 9-12].

The mechanisms and characteristics of electrode degradation are a vastly researched area, especially in the field of alkaline electrolysis [8-16]. These mostly involve the reduction in electrolyte concentration and the use of electrocatalysts on the electrode surface to keep the high level electrochemical performance, whilst limiting electrode deactivation [15-19].

One potential method of degradation reduction which has not been utilised in the field of electrolysis is the use of an 'oxygen-getter'. An oxygen-getter is titanium or an alloy of titanium in the form of either sponge, chips or bar stock. The purpose of the oxygen-getter is to provide cathodic protection to the electrode material from the corrosive medium during the electrolysis process [20].

Titanium exhibits a strong affinity to oxygen compared to nickel as it has a much lower electronegativity $\chi$; hence, it attracts electrons more freely which is why titanium has been chosen over other metals and it will protect the electrodes from cathodic attack by oxygen molecules in the solution. This enables the concentration and temperature of the aqueous solution to be increased, which in turn will increase the rate of electrolysis, without corroding the electrode itself [20].

In this case, titanium chips $(10 \mathrm{~mm} \times 10 \mathrm{~mm} \times 1 \mathrm{~mm})$ must be added $\left(240 \mathrm{~cm}^{2}\right.$ total surface area) to ensure that the electrode material is protected from cathodic corrosion. The titanium chips will be held at the bottom of the reaction vessel under a nickel mesh to ensure they do not interact with the electrochemical reaction. The specified dimensions were chosen for this feasibility study to maximise the surface area in the small volume available at the underside of the vessel, and if proven, further research could be conducted on varying geometries and loadings of titanium in the system. A larger size of titanium chips would limit the surface area available in the vessel and the subsequent electronegativity of the titanium. It is vital that the titanium does not participate in the electrochemical reaction and is only present to attract $\mathrm{O}^{2-}$ ions away from the nickel and to the titanium.

\section{Experimental materials and procedure}

Two electrolysers (Cells A and B) were built in a Perspex casing consisting of six nickel (201) electrodes $(100 \mathrm{~mm} \times 100 \mathrm{~mm} \times 1 \mathrm{~mm})($ total electrode surface area $1,206 \mathrm{~cm}^{2}$ ) connected in parallel with a fixed separation distance of $6 \mathrm{~mm}$. There is a clearance of $20 \mathrm{~mm}$ from the

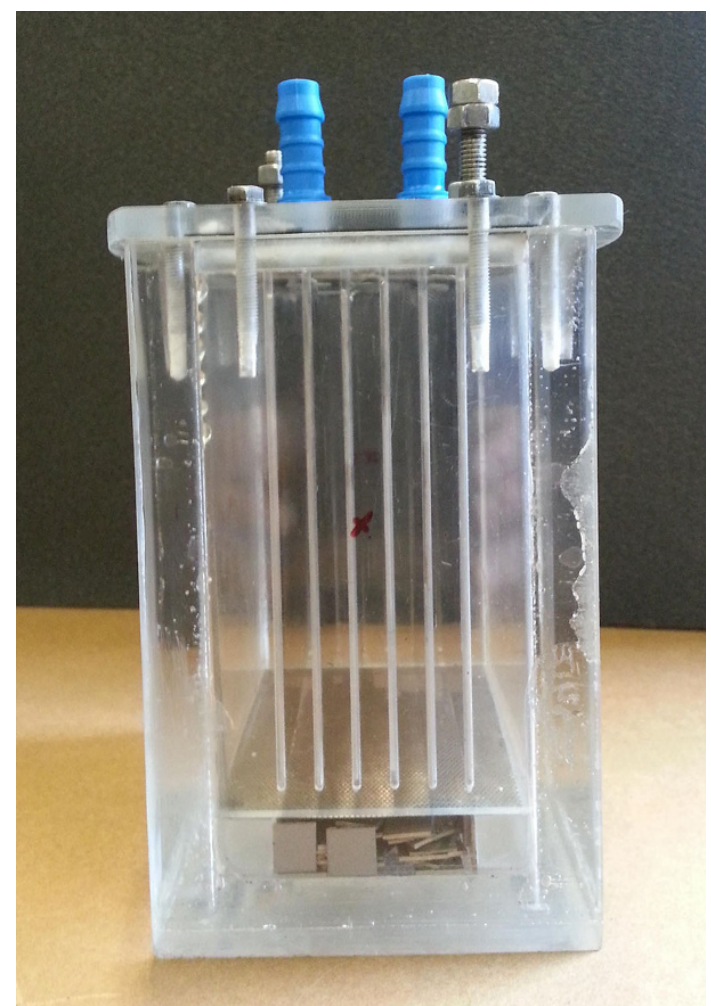

Fig. 1 Custom built alkaline electrolyser

bottom of the Perspex vessel to the bottom of the nickel electrodes. Cell A is the above-mentioned electrolyser stack without titanium [Grade I (ASTM B265)] chips, whilst Cell B has the titanium chips in the bottom of the vessel. A schematic of the electrolyser is shown in Fig. 1.

The potassium hydroxide ( $\geq 85 \% \mathrm{KOH}$ basis, pellets) was mixed with a specific volume of Type II Deionised Water [Millipore Distilled Water Purification System (Rios Doi3)], to produce a predetermined concentration of $\mathrm{KOH}$ solution. The potential was controlled, and the subsequent current measured using a direct current power supply (Thurlby Thandar Instruments QPX1200SP model).

Following the electrolysis reaction, the electrodes were prepared for SEM (JEOL JSM-6610LV), EDX (Oxford Instruments Inca 300 EDS system) and XPS (Thermo Scientific K-Alpha) analysis, were washed thoroughly with Type I (18 M $\Omega$ ) water to remove any residual $\mathrm{KOH}$ solution and then subsequently dried.

\section{Experimental results}

This section is divided into two sections for determine the performance variation between Cell A and Cell B. The first section compares the differences in electrochemical performance, and the second section compares the surface characteristics between the two electrolysers. 

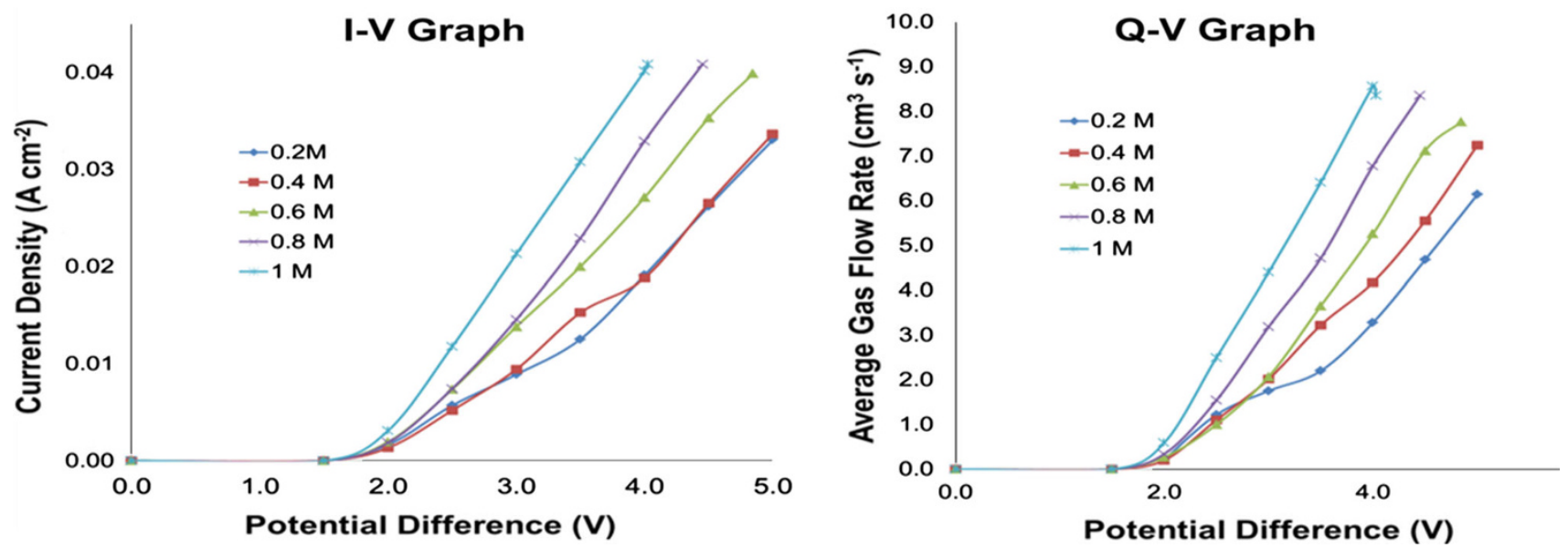

Fig. 2 IV characterisation and gas productivity curves

\section{Electrochemical analysis}

Cells A and B underwent electrochemical analysis to characterise current flow, gas productivity and long term degradation testing to quantify loss of electrochemical performance from being subject to a caustic alkaline environment on a 2-week basis.

IV analysis and gas productivity curves

The voltage was varied and the current flow recorded to characterise the electrochemical performance of the electrolyser. This analysis shows the resistances, known as overpotentials, in the electrolyser. The standard potential of electrolysis $(1.23 \mathrm{~V})$ and the thermo-neutral voltage $(1.48 \mathrm{~V})$ must be overcome for a current to flow between the electrodes. In reality overpotentials such as activation (the energy needed to overcome the activation energy needed for the reaction to occur), ohmic (energy needed to overcome the resistance to ion transfer in the electrolyte) and bubble (energy needed to overcome the reduction in nucleation sites on the electrode due to bubble evolution), the exist and addition energy is required in the system to overcome these.

This analysis was completed for various concentrations $(0.2-1 \mathrm{M})$ of $\mathrm{KOH}$ solution. Figure 2 shows the results for both Cells A and B which are the same, thus proving that the two electrolysers are identical in electrochemical performance and suffer the same overpotential.

Using the same methodology for $0.2-1.0 \mathrm{M} \mathrm{KOH}$ solution, the gas production rates were measured to quantify the enhancement in the conductivity of the electrolyte solution and the corresponding production of hydrogen and oxygen (HHO) gas.

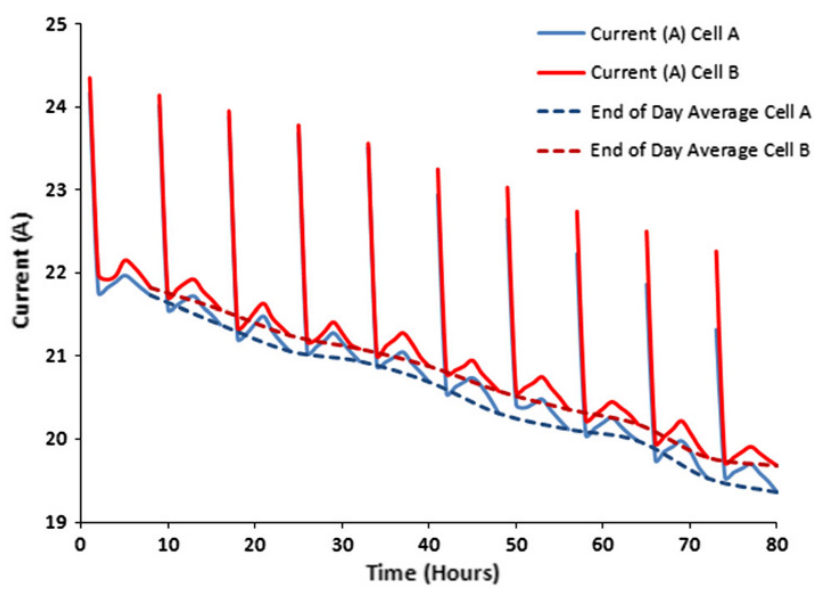

Fig. 3 Two-week electrochemical testing

\section{Degradation testing}

The aim was to test both cells for a total of 10 days ( 2 weeks), to mimic real-world utilisation of an electrolyser $(8 \mathrm{~h} \times 5$ days a week). Figure 3 shows the constant voltage performance for both Cells for the 10-day duration. Note that the electrolyte solution was not changed throughout testing of each cell and were left in solution and in standby mode for 2 days between Days 5 and 6 (weekend).

Through $8 \mathrm{~h}$ of testing, the initial current spike quickly decreases after a few minutes before increasing again through the rise in temperature of the electrolyte as a result of the electrochemical reaction. The current reaches a constant when the temperature of the electrolyte solution reaches its maximum (dependant on the input potential), and then the current subsequently decreases, whilst the temperature remains constant, due to oxide layer formation on the electrode surface. 
In Fig. 3, the general trend shows that the current reduces over time and is an expected result due to the degradation of the nickel electrodes. Throughout the testing, Cell B, the modified cell, shows degradation to a lesser extent than Cell A and the current is consistently higher. This helps to support our hypothesis that the titanium oxygen-getter concept could be used in this application to help protect the nickel electrodes due to possessing a higher affinity for oxygen from degradation.

The biggest difference that the titanium chips, in Cell B, have appeared to make is between Days 5 and 6 where the electrodes were left in the $\mathrm{KOH}$ solution over the weekend to further simulate industrial use. After the 2 days of no use, the Cell B current was 0.3 A higher than Cell A. This further supports the hypothesis showing that titanium has protected the electrodes even when there is no current flow.

Although in reality electrolysers operate for much longer than 2 weeks, the variation in electrochemical performance between Cell A and B is evident after 2 weeks operation. Whilst the experimental duration could be extended, the author feels that the feasibility of the principle which is being investigated here has been proven. Further study will analyse longer durations of electrolyser operation.

\section{Surface analysis}

Analysis of the nickel electrode surface is important to quantify oxide layer formation on the surface. The oxide layer coverage limits the number of nucleation sites available for bubble evolution to occur, thus reducing the efficiency of the electrolyser. The nickel and titanium from the electrolysers will undergo scanning electron microscopy (SEM) and energy dispersive X-ray spectroscopy to analyse any potential reduction in oxide layer formation as a result of introducing titanium to the electrolysis environment.

The metallic samples were split into five categories: (1) new nickel, (2) nickel from Cell A, (3) nickel from Cell B, (4) new titanium and (5) titanium from Cell B. These were each analysed by the before mentioned techniques.

SEM—nickel (1,2 and 3)

The SEM images of the new nickel were taken to provide a control sample against which the used electrode surfaces could be compared to see how the action of the electrolysis reaction affects the nickel surface.

The vertical line patterning is believed to be caused by the cutting of the sample. The thick bright strip on the edge of the sample in Fig. 4 is believed to be the side of the sample (caused by the cutting of the large plate into chips) reflecting light, rather than an indication of the presence of any foreign substance on the surface (to be confirmed by EDX).

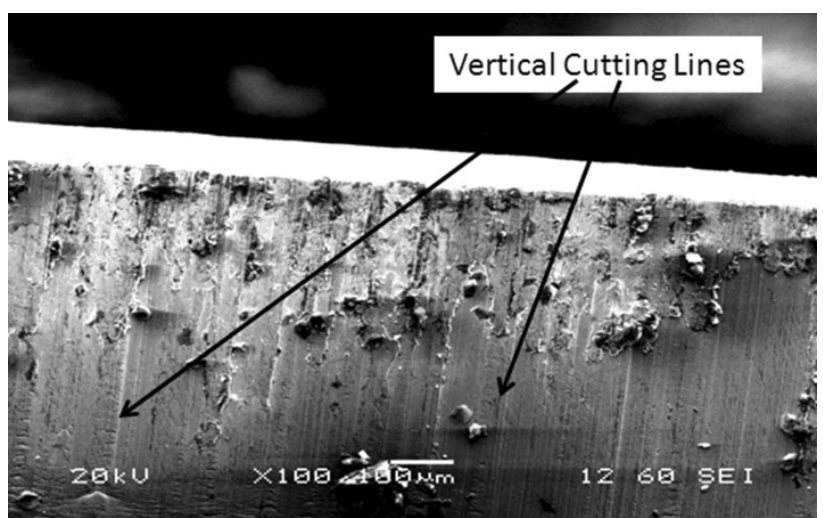

Fig. 4 New nickel cross-sectional view (×100 magnification)



Fig. 5 Nickel (Cell A) cross-sectional view ( $\times 100$ magnification)

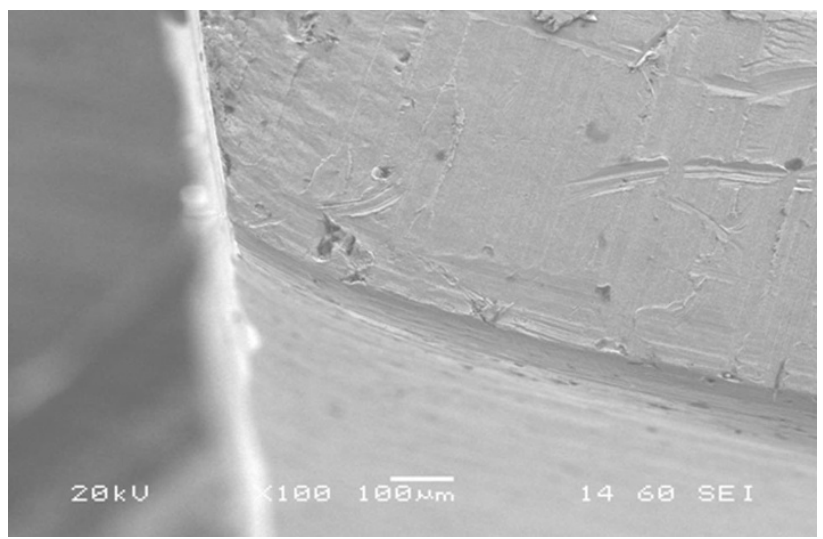

Fig. 6 Nickel (Cell B) cross-sectional view ( $\times 100$ magnification)

On the cross-sectional images of the nickel used in Cell A give very clear evidence of oxide layer formation. From observing the cross-sectional view of the sample, the oxide layer build-up is visible. Figure 5 shows a striking visual contrast between the nickel in the body of the sample and the edge of the sample. 

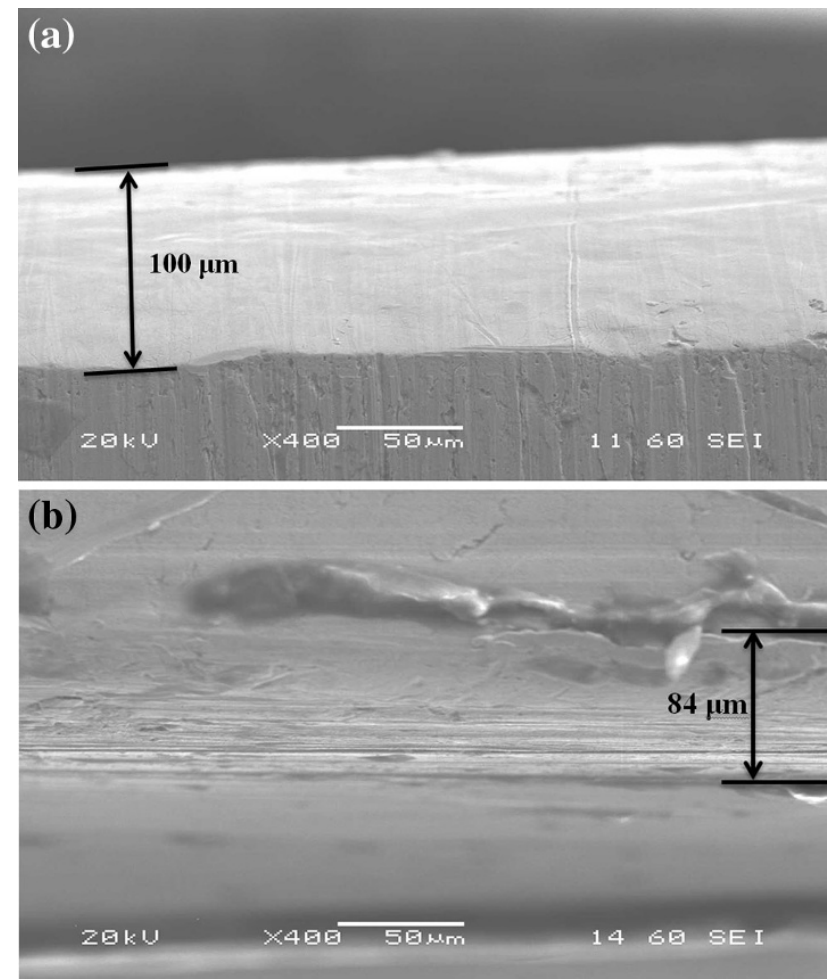

Fig. 7 a (Cell A) High magnification nickel cross-sectional view. b (Cell B) High magnification nickel cross-sectional view

The cross-sectional view of Cell B nickel (Fig. 6) shows a similar contrast between the nickel body and the edge of the sample to Cell A. Whilst in Cell A, the potential 'oxide layer' and the nickel body were different colours, in this image that is not the case, and the image is far more homogenous (Fig. 6). Despite this, it is believed that an oxide layer is evident in this image due to the strong horizontal marking on the lower side of the metal edge in both images consistent with Fig. 5 and different from the new nickel sample (Fig. 4).

There is also horizontal marking within the white region of Fig. 6, suggesting that it is laid on not all at once, but through a series of layers, very likely induced by the repeated exposure to the electrolysis reaction. The thickness of the oxide layers for Cell A and Cell B can be found in Fig. 7a, b.

The irregular build-ups seen in the middle of Fig. 7a indicate that material has been deposited, rather than the material being of homogeneous construction. In Fig. 7b, the oxide layer starts on the faint horizontal line between the anomalous deposits, which is highlighted by the thick black line in Fig. 7b. Using these markings, the oxide layer thickness measured from Fig. $7 \mathrm{~b}$ is $84 \mu \mathrm{m}$. This indicates a $16 \%$ reduction in oxide layer thickness from Cell A.

\section{Titanium-(4 and 5) SEM}

Similarly to the nickel, a new titanium sample was imaged to have a control sample against which the used titanium

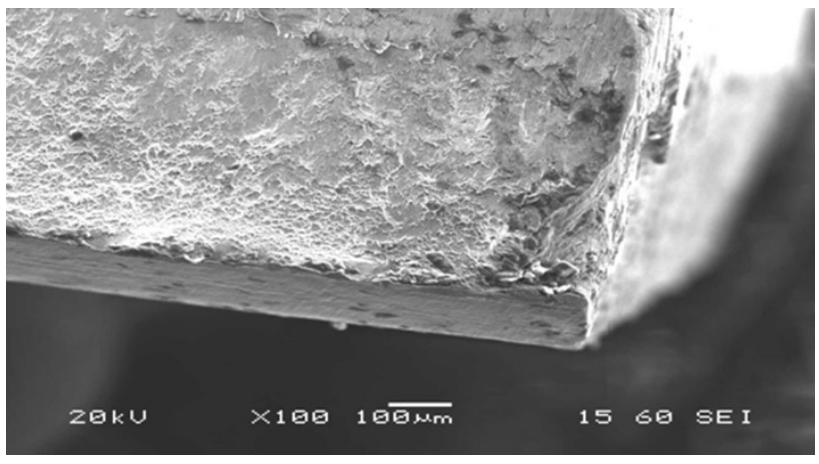

Fig. 8 New titanium cross-sectional view $(\times 100$ magnification $)$

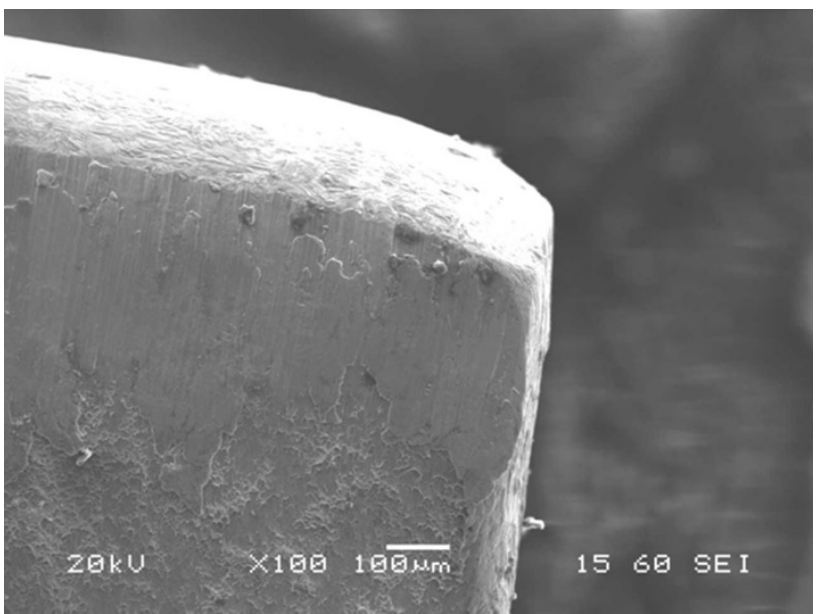

Fig. 9 Titanium (Cell B) cross-sectional view $(\times 100$ magnification $)$

could be compared. The cross-sectional view of the titanium control sample (Fig. 8) shows very clearly where the sample has been cut, exhibiting a smooth edge on the outer side, but most of the edge is made up of small peaks where the titanium has deformed during the cutting process. In terms of any potential oxide layer, there is no marking or colour change to potentially indicate that the surface of the new titanium has been compromised.

Evidence of oxide deposition is shown in the crosssectional images of Cell B titanium on the lower magnification image (Fig. 9); there is a clear colour change between the titanium and the oxide layer, as well as there being very strong horizontal marking in the white oxide layer; this is despite the fact that there is faint vertical marking on the titanium.

These effects are more noticeable in the higher magnification image (Fig. 10). The much stronger horizontal marking in the oxide layer seem to show titanium's greater affinity for oxygen, as does the oxide layer thickness, 


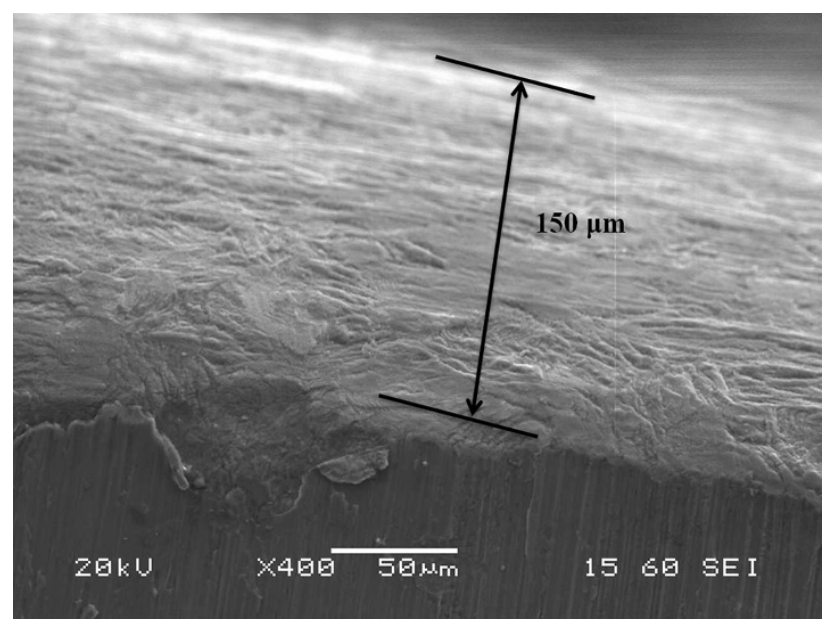

Fig. 10 Titanium (Cell B) cross-sectional view ( $\times 400$ magnification)

Table 1 EDX surface composition on nickel samples

\begin{tabular}{llll}
\hline Sample & Atomic\% & & \\
\cline { 2 - 4 } & Nickel & Titanium & Oxygen \\
\hline New nickel & 0.40 & 0.00 & 18.2 \\
Cell A nickel & 0.21 & 0.00 & 31.1 \\
Cell B nickel & 0.27 & 0.01 & 25.9 \\
\hline
\end{tabular}

which from Fig. 10 is shown to be $150 \mu$ m, nearly twice that of the corresponding nickel sample.

EDX—nickel (1, 2 and 3)

For all nickel samples, analysis carried out at $500 \times$ magnification focused on the planar surface of each sample. Damage to the surface from the electrolysis process may have allowed other metals to be present on the surface and any deposits found (predominantly after use) would be investigated to see if this was a large increased build-up of oxide layer. The atomic\% for nickel, titanium and oxygen for the nickel samples is shown in Table 1.

When comparing the flat surface spectra data for the control sample, Cell A and B, the main differences are the levels of nickel and oxygen. A 12.9 atomic\% increase in oxygen content appears on Cell A nickel compared to the unused sample, which coincides with a 0.19 atomic\% decrease in nickel content between the two samples.

There is a 5.2 atomic\% decrease in oxygen content on the nickel surface of Cell B compared to Cell A showing that the presence of the titanium has reduced the quantity of oxide layer formation, helping to reduce the rate of nickel electrode degradation. This is further evident with the increase of 0.06 atomic\% nickel content on the Cell B nickel relative to Cell A nickel.
Table 2 EDX surface composition on titanium samples

\begin{tabular}{llll}
\hline Sample & Atomic\% & & \\
\cline { 2 - 4 } & Nickel & Titanium & Oxygen \\
\hline New titanium & 0.00 & 0.22 & 27.5 \\
Cell B titanium & 0.01 & 0.19 & 322 \\
\hline
\end{tabular}

Table 3 XPS Surface analysis of nickel and titanium samples

\begin{tabular}{llll}
\hline Sample & \multicolumn{2}{l}{ Atomic\% } & \\
\cline { 2 - 4 } & Nickel & Titanium & Oxygen \\
\hline New nickel & 0.36 & 0.01 & 15.0 \\
Cell A nickel & 0.19 & 0.02 & 29.5 \\
Cell B nickel & 0.26 & 0.02 & 24.5 \\
New titanium & 0.01 & 0.12 & 25.0 \\
Cell B titanium & 0.02 & 0.09 & 29.5 \\
\hline
\end{tabular}

EDX-titanium (4 and 5)

The EDX data for new and used titanium is shown in Table 2.

Cell B titanium shows an increase in oxygen content when compared to the control sample (4.7 atomic\%). This shows that an oxygen layer is present, which is consistent with titanium having a higher affinity for oxygen than nickel. Analysis on the used titanium content of the samples shows a 0.3 atomic\% decrease, consistent with the increased oxygen content on the titanium Cell B sample.

X-ray photoelectron spectroscopy (XPS)

To support the EDX evidence provided, the samples (1-5) also underwent XPS analysis for further verification of the surface composition. Both nickel (1-3) and titanium (4-5) samples were analysed for nickel, titanium and oxygen content on the samples. The peaks were then integrated to determine the surface elemental composition in atomic\%. This is shown in Table 3.

Table 3 shows a $94 \%$ increase in oxygen concentration on the nickel surface from new nickel to nickel in Cell A and then a $17 \%$ decrease in when compared to nickel from Cell B. This is consistent with the analysis shown in the SEM and EDX analysis.

The metallic composition shows a $43 \%$ decrease in nickel content on the Cell A nickel compared to the new nickel samples and a $25 \%$ increase in nickel content of Cell B compared to Cell A nickel. The titanium content on the titanium samples decreases by $23 \%$ on the Cell B titanium when compared to the new titanium sample, consistent with the hypothesis of this paper. 


\section{Conclusions}

The research has analysed the effect of introducing titanium to the alkaline electrolysis system as a sacrificial metal. The electrochemical performance of Cell A decreased at a faster rate than that of Cell B, specifically after a 2-day stationary period. The only variable between the cells is the titanium; therefore, this is the determining factor in the improved electrochemical performance of Cell $\mathrm{B}$ when compared with that of Cell A.

The conclusions drawn from the electrochemical analysis is backed up with the findings from the surface analysis. This also points towards a decrease in oxide layer formation on the nickel electrode in Cell B when compared to that in Cell A. The elemental composition of the surface of nickel and titanium from Cells A and B has shown an increased presence of oxygen on the electrode surface. The thickness in oxide layer on the nickel from Cell B is $17 \%$ less than in Cell A. This limits the number nucleation sites on the electrode surface and links to reduced electrochemical performance in Cell A than in Cell B.

It is concluded that the presence of titanium as a sacrificial metal in an alkaline electrolysis system with nickel electrodes increases the electrical efficiency and decreases the rate of electrode degradation over 2 weeks of operation.

Future work in this field will investigate the use of different titanium geometries, for example sponges, plates and spheres, and the effect that varying titanium loadings has on the thickness of oxide layer formation on nickel electrodes in an alkaline electrolyser.

Acknowledgments I would like to acknowledge supervisors and colleagues at the Centre for Hydrogen and Fuel Cell Research, University Birmingham, UK. I would also like to give thanks the Engineering and Physical Sciences Research Council for funding my $\mathrm{Ph} . \mathrm{D}$. as part of the Doctoral Training Centre in Hydrogen, Fuel Cells and their Applications. I also express my gratitude to the National EPSRC XPS Users Service (NEXUS) for their assistance with XPS analysis completed in this research.

Open Access This article is distributed under the terms of the Creative Commons Attribution License which permits any use, distribution, and reproduction in any medium, provided the original author(s) and the source are credited.

\section{References}

1. Bičáková, O., Straka, P.: Production of hydrogen from renewable sources and its effectiveness. Int. J. Hydrogen Energy 37(16), 11563-11578 (2012)

2. Holladay, J., Hu, J., King, D., Wang, Y.: An overview of hydrogen production technologies. Catal. Today 130, 244-260 (2009)
3. Lu, P., Srinivasan, S.: Advances of water electrolysis technology with emphasis on use of the solid polymer electrolyte. J. Appl. Electrochem. 9(3), 269-283 (1979)

4. Marini, S., Salvi, P., Nelli, P., Pesenti, R., Villa, M., Berrettoni, M., Zangari, G., Kiros, Y.: Advanced alkaline water electrolysis. Electrochim. Acta 82, 384-391 (2012)

5. Zoulias, E., Varkaraki, E., Lymberopoulos, N., Christodoulou, C., Karagiorgis, G.: A review on water electrolysis. TCJST 4(2), 41-71 (2004)

6. Harrison, K., Levene, J.: Electrolysis of water. In: Rajeshwar, K., McConnell, R., Licht, S. (eds.) Solar Hydrogen Generation: Toward a Renewable Future, pp. 41-63. New York: Springer (2008)

7. Symes, D., Al-Duri, B., Dhir, A., Bujalski, W., Green, B., Shields, A., Lees, M.: Design for on-site hydrogen production for hydrogen fuel cell vehicle refuelling at University of Birmingham, U.K. Energy Proc 29, 606-615 (2012)

8. Zeng, K., Zhang, D.: Recent progress in alkaline water electrolysis for hydrogen production and applications. Prog. Energy Combust. Sci. 36(3), 307-326 (2010)

9. Nikolic, V., Tasic, G., Maksic, A., Saponjic, D., Miulovic, S., Kaninski, M.: Raising efficiency of hydrogen generation from alkaline water electrolysis-energy saving. Int. J. Hydrogen Energy 35(22), 12369-12373 (2010)

10. Zhang, H., Lin, G., Chen, J.: Evaluation and calculation on the efficiency of a water electrolysis system for hydrogen production. Int. J. Hydrogen Energy 35(20), 10851-10858 (2010)

11. Mazloomi, S., Sulaiman, N.: Influencing factors of water electrolysis electrical efficiency. Renew. Sustain. Energy Rev. 16(6), 4257-4263 (2012)

12. Bird, R., Steward, W., Lightfoot, E.: Transport Phenomena, 2nd edn. New York: Wiley (2002)

13. Santos, D.M.F., Sequeira, C.A.C., Macciò, D., Saccone, A., Figueiredo, J.L.: Platinum-rare earth electrodes for hydrogen evolution in alkaline water electrolysis. Int. J. Hydrogen Energy 38(8), 3137-3145 (2013)

14. Matsushima, H., Fukunaka, Y., Kuribayashi, K.: Water electrolysis under microgravity part II: description of gas bubble evolution phenomena. Electrochim. Acta 51(20), 4190-4198 (2006)

15. Mauer, D., Kirk, D., Thorpe, S.: The role of iron in the prevention of nickel electrode deactivation in alkaline electrolysis. Electrochem. Acta 52(11), 3503-3509 (2007)

16. Bocca, C., Barbucci, A., Cerisola, G.: The influence of surface finishing on the electrocatalytic properties of nickel for the oxygen evolution reaction (OER) in alkaline solution. Int. J. Hydrogen Energy 23(4), 247-252 (1998)

17. Abouatallah, R., Kirk, D., Thorpe, S., Graydon, J.: Reactivation of nickel cathodes by dissolved vanadium species during hydrogen evolution in alkaline mixture. Electrochim. Acta 47(4), 613-621 (2001)

18. Marceta Kaninski, M., Maksic, A., Stojic, D., Milljanic, Š.: Ionic activators in the electrolytic production of hydrogen-cost reduction-analysis of the cathode. J. Power Sources 131(1-2), 107-111 (2004)

19. Eigeldinger, J., Vogt, H.: The bubble coverage of gas-evolving electrodes in flowing electrolyte. Electrochim. Acta 45(27), 4449-4456 (2000)

20. Faison, J.A., Paton, N.E., Thornton, T.J.: Method for removing ceramic material from castings using caustic medium with oxygen getter, U.S. Patent 5,679,270, filed July 1, 1996, and issued October 21, 1997 